\title{
The direct costs of drug-induced skin reactions
}

\author{
Nina Kiepurska', Elwira Paluchowska', Witold Owczarek', Monika Szkultecka-Dębek', \\ Karina Jahnz-Różyk ${ }^{2}$ \\ ${ }^{1}$ Department of Dermatology, Military Institute of Medicine, Warsaw, Poland \\ ${ }^{2}$ Department of Immunology and Allergology, Military Institute of Medicine, Warsaw, Poland \\ Kiepurska N, Paluchowska E, Owczarek W, Szkultecka-Dębek M, Jahnz-Różyk K. The direct costs of drug-induced skin reactions. Ann Agric \\ Environ Med. 2017; 24(2): 190-193. doi: 10.5604/12321966.1235168
}

\begin{abstract}
Objective. The aim of the study was an assessment of direct costs of patients hospitalised for for skin adverse drug reactions during 2002-2012 in the Department of Dermatology at the Military Institute of Medicine (Ministry of Defence) in Warsaw. The analysis was carried out from the perspectives of the public payer and service provider.

Materials and method. The retrospective study was carried out in a group of 164 adult patients due to skin adverse drug reactions. Analysis was based on data from patient medical records and medical orders which provided information on the used resources, including diagnostic tests, medical consultations, medicinal products, hospitalisation duration, together with cost estimation, regardless of the treatment being the cause of the skin reaction.

Results. According to the International Statistical Classification of Diseases and Related Health Problems(ICD) diagnosis and scores, assigned by the National Healthcare Fund, it has been estimated that patient hospitalisation at the Department of Dermatology for skin drug reaction incurred costs at the average amount of $€ 717.00$ per patient. The complex diagnostics and pharmacotherapy of the same group of patients generated costs for the hospital at the average amount of $€ 680$ per patient.

Conclusions. As a result of the analysis, the therapy for skin adverse drug effects generates significant costs, both for the payer and the service provider. Since the costs are comparable, it seems that the pricing of medical procedures by the public payer is adequate for the costs incurred by the medical service provider.
\end{abstract}

Key words

adverse drug reactions, direct costs, ICD 10, JGP, National Health Fund

\section{INTRODUCTION}

Adverse effects of drugs still pose a major challenge for physicians, regarding clinical and diagnostic issues in various fields of medicine. Following the definition of the European Medicines Agency (EMA), adverse drug reaction is a is noxious and unintended response to a medicinal product [1]. The administered drugs may induce severe, adverse conditions, requiring intervention in a hospital environment [2]. The incidence of adverse drug effects is estimated at approximately $5-10 \%$ of all hospitalised patients [3], of whom $30 \%$ include skin adverse drug reactions (ADR) [4]. Drug-induced skin reactions may be found in various age intervals; however, their prevalence is higher in adults than in children.

For the last few years, the role of economic analyses in the reimbursement decision- making process is increasing, both in Poland and worldwide. Such analyses include evaluations of applied therapy costs. The results of these studies are often of significance, supporting decisions, which implement new and/or modify actual therapeutic standards. Following the Polish Law, an assessment of the economic component is obligatory in drug reimbursement approving procedure, in order to optimise the allocation of funds by the public payer. Economic analyses as part of the Health Technology Assessment (HTA) dossier are evaluated by experts of the Agency for Health Technology Assessment, and the process is completed by a recommendation for a new technology issued by the Chairman of the Agency for the Minister of Health.

Address for correspondente: Monika Szkultecka-Dębek, Department of Dermatology, Military Institute of Medicine, Warsaw, Poland

E-mail: monika.sz.debek@gmail.com

Received: 31 October 2013; accepted: 8 October 2015; first published February 2017
Significant tasks of the HTA include efficacy and safety analyses. Reviewing international publications and a growing interest in the economic component of ADRs treatment is observed in many countries $[5,6]$. In Poland, some clinical pharmacology centres evaluate the efficacy and costs of therapies in broad pharmacoeconomic evaluation programmes $[7,8]$. However, during a literature search, no analyses have been identified dedicated to adverse drug effects associated with skin reactions, and the costs of their treatment in Polish conditions. This study attempts to estimate the costs of therapy in cases of drug-induced skin reactions in Polish conditions.

\section{OBJECTIVE}

The aim of the analysis was to estimate the direct costs (pharmacotherapy, laboratory tests, medical consultations), incurred with regards to patients hospitalised at the Department of Dermatology, Military Institute of Medicine (Ministry of Defence) in Warsaw during 2002-2012 due to drug-induced skin reactions, from the perspective of the public payer and the medical service provider.

\section{MATERIALS AND METHOD}

The retrospective study was carried out in a group of 164 adult patients, 57 men and 107 women, hospitalised for druginduced skin reactions in the Department of Dermatology at the Military Institute of Medicine during 2002-2012. The mean age of the patients was 53.7 years. All the included patients were hospitalized due to adverse, drug-induced skin 
reactions, regardless of administered therapy. The analysis focused on treatment patterns of adverse skin reactions and data collected on the resources used.

Evaluation and analysis. An evaluation was performed from two different perspectives: public payer and of the medical service provider. Direct costs of treatment of skin adverse drug effects were evaluated in patients hospitalised between 2002-2012. The analysis was based on data from patients' medical records and from medical order cards. These documents provided information on the resources used, such as diagnostic tests, specialist consultations, medicinal products used for treatment and hospitalisation time. Based on the identified resources used in the applied treatment, the costs of therapy were estimated.

Taking into account changes in the system of settlements during the analysed period and to ensure a consistent and unified approach in calculations, a one-year time horizon was applied in the analysis. In the analysis, performed from the public payer's perspective, price lists published by the National Health Fund and lists of drugs reimbursed by the Ministry of Health, and valid since the end of 2012, were used as publicly available source data for cost calculations. Additionally, taking into account calculations from the medical service provider's perspective, data for 2012 were collected from the Hospital's Department of Organisation and Accounts.

Analysing the costs of patients' hospitalisation for druginduced skin reaction treatment, depending on the accepted perspective, either the costs incurred by the public payer in compliance with the Act on medical services, financed from public funds, or the costs incurred by the hospital, were taken into account.

For the calculations from the public payer's perspective, the costs of specialist consultation visits (dermatologist), laboratory diagnostic tests and hospitalisations were taken into account on the basis of prices for medical services, determined by the National Health Fund via contracts with healthcare units, following the Act on medical services financed from public funds in 2012. In the case of a contract with the National Health Fund, the costs of laboratory tests, other diagnostic tests and pharmacotherapy were included in the costs of the so-called specialist visit. The value of service costs incurred by the National Health Fund was based on the International Statistical Classification of Diseases and Related Health Problems - ICD 10, and the Diagnosis Related Groups (DRG).

From the perspective of the medical service provider (the hospital), the direct medical costs were accounted, including the costs of pharmacotherapy, medical consultations (visits), laboratory tests and hospitalisation. The costs of pharmacotherapy were calculated on the basis of the wholesale prices for drugs, fixed for the year 2012. The unit costs of laboratory tests, consultations and hospitalisation days were taken from the hospital's internal price list prepared by the Department of Medical Service Sales and Analysis of the Military Institute of Medicine for 2012.

Additionally, the costs, incurred by the public payer after hospitalisation until the end of therapy were calculated. For that purpose, the costs of outpatient therapy and outpatient visits were taken into account.

\section{RESULTS}

The most frequent forms of drug-induced skin reactions diagnosed in the study group included toxic-allergic dermatitis - $(52 \%)$, multiform erythema - $21 \%$, nodal erythema - 15\%, and the Stevens-Johnson Syndrome (SJS) - $4 \%$. Other causes, which accounted for $8 \%$ of cases, included contact dermatitis and allergic urticaria (Fig. 1). Following analysis of the medical records of 53 patients, a history of cutaneous hypersensitivity episodes was found, while in the other 111 patients no drug-induced skin reactions had occurred. On average, the symptoms of adverse drug reactions appeared on the skin surface after 7.4 days of drug use. The mean hospitalisation period was 4.84 days. In the study group, the most frequent causes of drug-induced skin reactions were beta lactam antibiotics, beta-lactam betalactamase inhibitors, first generation cephalosporins and non-steroidal anti-inflammatory drugs (Fig. 2).

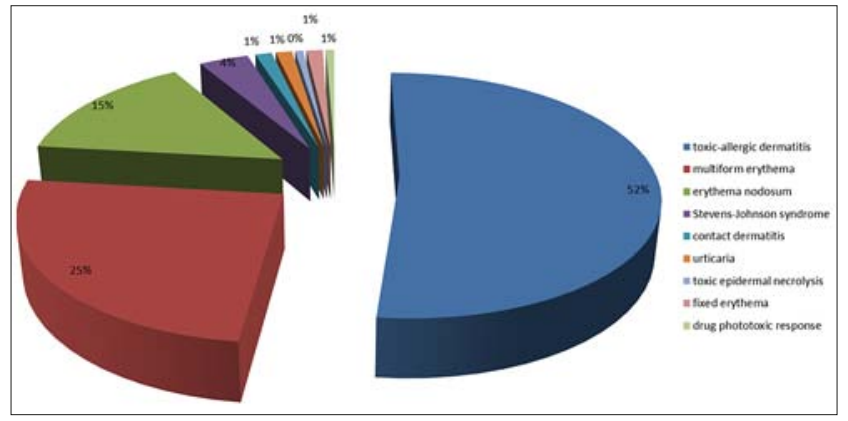

Figure 1. The most frequent forms of drug-induced skin reactions

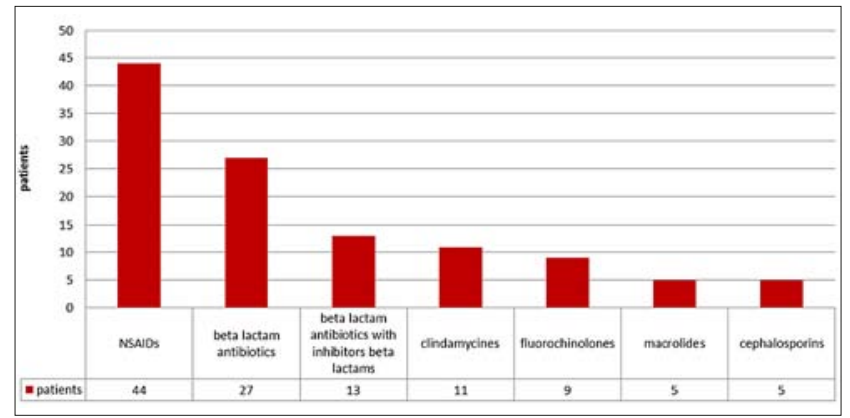

Figure 2. The most frequent causes of drug-induced skin reactions

Hospital patient accounting by the public payer included assigning the patient to specific diagnosis-related groups (DRGs) [9]. The patients were qualified to particular DRGs, according to ICD-10-defined diagnosis. In the analysed group, three DRGs were defined: severe dermatological diseases J 38 (L27.0 generalized skin eruption due to drugs and medicaments, L27.9 dermatitis due to unspecified substance taken internally, serious dermatological diseases J 39 (L 51.1 bullous erythema multiforme (Stevens-Johnson syndrome), L51.9 erythema multiforme, unspecified, L52.0 erythema nodosum, L56.0 drug phototoxic response), and mild dermatological disease J 49 (L50.0 allergic urticaria). Following DRG classification, the National Health Fund assigned the following scores: 82 for J38, 33 for J39 and 27 for J39. A score of one equalled $€ 12.5$ (for 2012). The total cost of hospitalisation, based on the scores assigned by the National Health Fund and resulting from the Act on medical services financed from the public funds, amounted in the analysed 
Table 1. Direct costs of drug-induced (pharmacotherapy, diagnostic) skin reactions

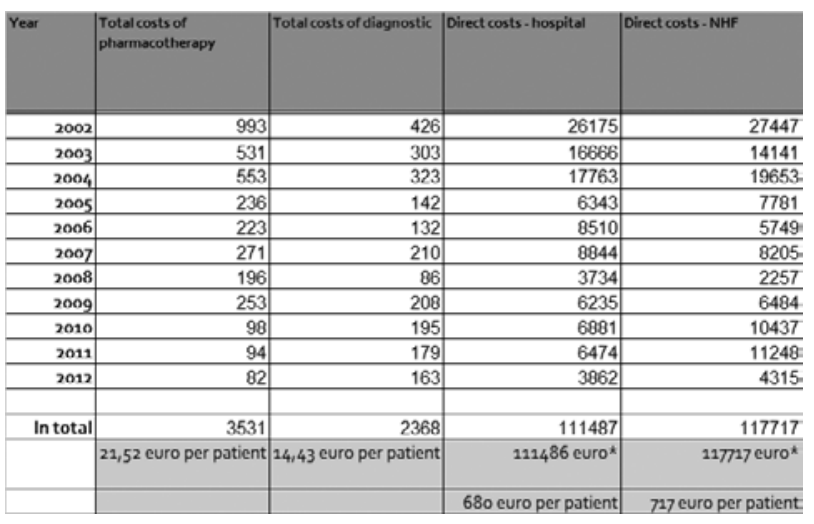

* EUR $=4.20$ PLN

group during 2002-2012 to €117,717. The average cost per patient was $€ 717$ (Tab. 1).

Analysing the direct medical costs from the medical provider's perspective, the total costs of performed diagnostic and laboratory tests (including haematology, biochemistry, urine tests, lipid profile, x-ray examination), incurred by the hospital, were calculated and amounted to $€ 2,367$. The average examination and test costs per patient were $€ 14.43$. The total cost of pharmacotherapy (glycocorticosteroid therapy and antibiotic therapy), applied in 164 patients was $€ 3,530$, and the average cost of pharmacotherapy per one patient was $€ 21.52$.

The total costs of hospitalisation in the analysed period incurred by the Military Institute of Medicine, and calculated according to the internal price list for the year 2012 for the analysed study group, amounted to $€ 111,486$ euro. The average hospitalisation cost per patient was $€ 680$.

Following the performed calculations, the average costs of treatment of one patient with drug-induced skin reactions, incurred by the National Health Fund, was $€ 717$ per patient, while the same cost from the hospital's perspective was $€ 680$. The charts show the total costs and average costs per patient each year. Slight differences in these costs are the result of the classification of dermatological diagnoses DRG groups for the National Health Fund, the length of hospitalization, and the related costs incurred by the service eprovider (Fig 3, 4).

In order to acquire a complete picture of the costs of therapy applied in cases of adverse drug effects, the analysis also took

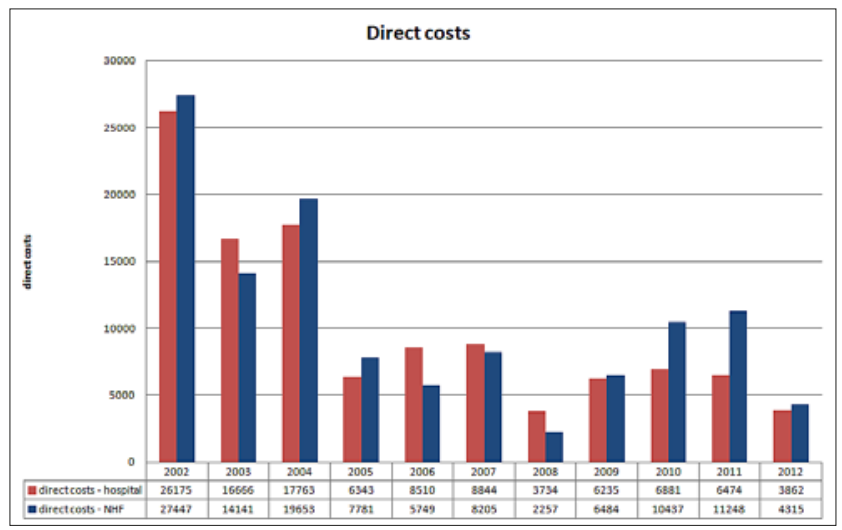

Figure 3. Direct costs of drug-induced skin reactions from the perspectives of public payer and service provider

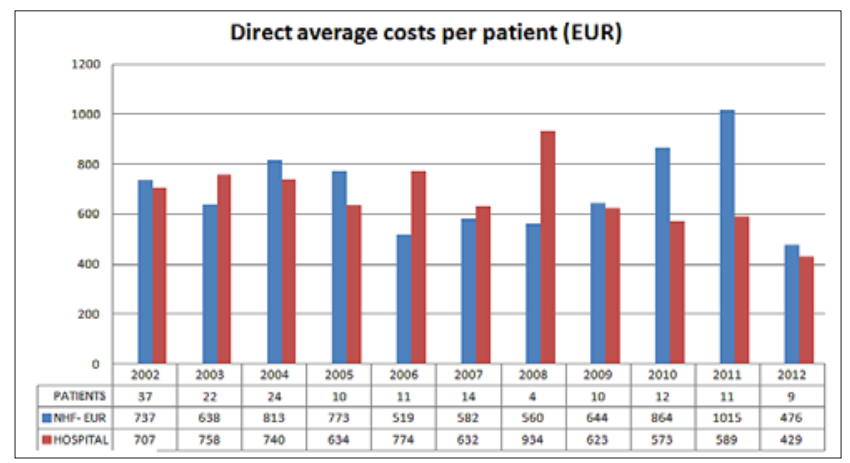

Figure 4. Direct average costs of drug-induced skin reactions

into account the costs of outpatient treatment, applied after discharge from hospital, and the costs of reimbursement drugs prescribed and used under outpatient conditions.

The costs of further treatment which the patient incurred in the course of outpatient treatment (total amount for drugs recommended for the period after hospital discharge, taking into account the reimbursement conditions for 2012), amounted to $€ 1,403$. In conversion to one patient, the average costs of outpatient pharmacotherapy was $€ 8.55$.

\section{DISCUSSION}

In the era of the launching of newer and newer medicinal agents onto the market, the issue of drug-induced reactions is constantly a valid issue, and a number of patients with adverse effects will still require treatment in a hospital environment. The diagnostics and therapy of hospitalised patients is not only a problem for physicians, but due to the generation of additional costs and impact on the payer's budget, pharmacoeconomists are also interested in the assessment of these costs. Accordingly, the authors of this study undertook an analysis of the direct medical costs incurred by the public payer and the medical service provider in the group of 164 patients in the study over a ten-year period. It was estimated that patient hospitalisation for skin adverse drug reactions treatment, diagnosed by ICD 10 and with scores assigned by the National Healthcare Fund, generated an average cost of $€ 717$ for the National Health Fund per one patient. The complex diagnostics and pharmacotherapy of the same group of patients generated average costs for the hospital in the amount of $€ 680$ per patient. The difference in the costs, incurred by the public payer and the medical service provider, was small, amounting to $€ 38$ euro per one patient.

Regarding the analysed group of patients, it may seem that the procedures of treatment of adverse drug effects were properly valuated and priced; however, the limitations and constraints of the performed analysis should be taken into account when discussing the results. First of all, the number of analysed events and the number of patients can be an important factor influencing the final result. It was assumed that during the process performed by the NHF in relation to different procedures of pricing, and to avoid similar limitations in the analysis, a broader perspective was applied. There were no reports in the available medical literature on evaluations of direct costs of therapy for druginduced adverse skin reactions. The Italian oncologists, Giuliani et al. (2012), estimated the direct costs of treatment of cutaneous eruption after cetuximab administered to 31 
patients for advanced colorectal carcinoma. The patients were monitored from June 2006 - May 2011. In 19 patients, toxic drug-induced dermatitis was observed in four intensity classes. The costs of treatment of the skin complications were estimated in the course of cetuximab therapy, approached from the perspective of eruption intensity and average duration, the analysis providing the average amount of between $€ 159.42-€ 294.50$ [10]. The majority of reports deal with systemic adverse drug reactions.

Rottenkolber et al. (2011) estimated the direct costs of patient hospitalisation during 2006-2007 at a German internal department for general adverse drug effects. A group of 1,834 patients was qualified into the study and data were acquired from the Net of Regional Pharmacovigilance Centres. The most frequent adverse drug effects included bleeding from the gastric system (16.5\%) and hypoglycaemia (13.3\%). The average hospitalisation period was 9.3 days and mean age of examined patients was 71 years. The average costs of hospitalisation per one patient were estimated at $€ 2,250$ (ranging from $€ 733$ - €17,482). No drug-induced skin reactions were described in the study. The high costs of hospitalisation for general adverse effects of drugs resulted from high financial outlays for pharmacotherapy and expensive diagnostics imaging, necessary for detailed diagnostics in the internal department [5].

In the same publication, Rottenkolber et al. presented the costs of in-patient treatment of general drug-induced reactions in other countries (France, Germany, Switzerland, England, the USA), recorded during 1997-2005. The average cost of hospitalisation for general drug-induced reactions in internal departments varied within the range $€ 2,068$ $€ 5,153$ per patient. The average hospitalisation duration was 6 - 14.7 days. A longer stay in hospital generated higher costs of treatment of general drug-induced reactions with neurological and haematological complications ranking the first among the described adverse effects. The evaluated group with concomitant, chronic diseases, may not be regarded as an unequivocal, objective reference, which may have influenced the level of estimated costs [5] which was rather high.

A year later, Rottenkolber et al. conducted a retrospective economic analysis in a group of 49,462 patients in three 3 hospitals in Germany. The data were collected from January December 2008. One of the analyses targeted the direct costs of therapies applied in cases of drug-induced adverse effects leading to hospitalisation in a group of 564 patients. The most frequent causes of hospitalisation included enteritis in the course of drug-induced infection with Clostridium difficile and psychic disorders after drug abuse. The average cost level per patient was $€ 1,978 \pm € 2,036$. The other analyses compared the costs of therapy for patients hospitalised for drug-induced adverse effects, with the costs of patients hospitalised without drug-induced adverse reactions (a control group matched by gender and age). The excess balance was $€ 970$ per patient in the group treated for drug-induced adverse effects. However, no data were provided regarding the cause for such a surplus [11].

In India, an economic evaluation was performed in a group of 92 patients, hospitalised from January - April 2005 for drug-related events (DRE). The most frequent causes of hospitalisation included non-compliance with doctor's recommendations (66\%), adverse drug reaction (28\%) and drug abuse $(6 \%)$ The average total costs of hospitalisation in a public hospital for the above-mentioned reasons were estimated and calculated per one patient in the amount of $€ 328$ (€15 - €740 euro). Direct costs were estimated at $€ 32$ per one patient, while indirect costs were much higher - €295. The direct costs of treatment in this case are relatively low because in public hospitals in India they are not accounted for during the initial 48 hours of hospitalisation [12].

\section{CONCLUSIONS}

The presented analysis demonstrates that therapies for druginduced, adverse skin reactions generate considerable costs, both for the payer and the service provider. The costs incurred by both parties are comparable, providing evidence that the pricing of procedures proposed by the public payer in Poland and valid since 2012, has been adequate for the expenses borne by the service provider.

\section{REFERENCES}

1. Laurence DR, Bennett PN, Brown MJ. Clinical Pharmacology, 8thedn. London: Churchill Livingstone, 1997.

2. Skibicka I, Maciejczyk A. Bezpieczeństwo farmakoterapii a zgłaszanie niepożądanych działań leków. Neurol. Neurochir. Pol. 2004; 84, 503-10.

3. Stausberg J, Hasford J. Drug-related admissions and hospital-acquired adverse drug events in Germany: a longitudinalanalysis from 2003 to 2007 of ICD-10-coded routinedata. Health Services Research 2011; 11:134.

4. Burbach, GJ, Zuberbier T. Diagnosis of drug-induced skin reactions: a future role for computer-aided systems? Curr Opin Allergy Clin Immunol. 2011 OCT; 11(5): 451-6.

5. Rottenkolber D, Schmiedl S, Rottenkolber M, Farker M, Saljé K, Mueller $S$, et al. Adverse drug reactions in Germany: direct costs of internal medicine hospitalizations. Pharmacoepidemiology and drug safety 2011; 20: 626-634.

6. Pattanaik S, Dhamija P, Malhotra S, Sharma N, Pandhi P. Evaluation of cost of treatment of drug-related events in a tertiary care public sector hospital in Northern India: a prospective study. Br J Clin Pharmacol. 2009 Mar; 67(3): 363-9.

7. Więczkowska H, Bryl W, Hoffmann K. Costs of diagnosis and treatment of hypertension in the department of internal diseases, Forum Zaburzeń Metabolicznych 2011, tom 2, nr 3, 177-183.

8. Kusowska J. Economic evaluation of treatment of community acquired respiratory tract infections. Farmakoekonomika 1/2001.

9. Grabowski J, Kozierkiewicz A, Gajek F. Polski system jednorodnych grup pacjentów, Służba Zdrowia nr 80-81, 18 października 2001.

10. Giuliani J, Indelli M, Marzola M, Raisi E, Frassoldati A. The management of skin toxicity during cetuximab treatment in advanced colorectal cancer: how much does it cost? A retrospecive economic assessment from a single-center experience Tumori 2012 Jul-Aug; 98(4): 408-12.

11. Rottenkolber D, Hasford J, Stausberg J. Costs of adverse drug events in German hospitals - a microcosting study. Value In Health (2012)8 68-875.

12. Pattanaik S, Dhamija P, Malhotra S, SharmaN, Pandhiet P. Evaluation of cost of treatment of drug-related events in a tertiary care public sector hospital in Northern India: a prospective study. British Journal of Clinical Pharmacology, Volume 67, issue 3 (March 2009), p. 363-369. 